\title{
The Role of IL-33-Dependent Inflammation in the Tumor Microenvironment
}

\author{
Marie-Hélène Wasmer ${ }^{1,2}$ and Philippe Krebs ${ }^{1 *}$ \\ ${ }^{1}$ Institute of Pathology, University of Bern, Bern, Switzerland, ${ }^{2}$ Graduate School for Cellular and Biomedical Sciences, \\ University of Bern, Bern, Switzerland
}

There is compelling evidence that inflammation contributes to tumorigenesis. Inflammatory mediators within the tumor microenvironment can either promote an antitumor immune response or support tumor pathogenesis. Therefore, it is critical to determine the relative contribution of tumor-associated inflammatory pathways to cancer development. Interleukin-33 (IL-33) is a member of the IL-1 family of cytokines that is released upon tissue stress or damage to operate as an alarmin. IL-33 has been primarily implicated in the induction of type-2 immune responses. However, recent findings have shown a role of IL-33 in several cancers where it may exert multiple functions. In this review,

OPEN ACCESS

Edited by:

Sophie Paczesny,

Indiana University School of

Medicine, USA

Reviewed by:

Anja Schwenzer,

Oxford University, UK

Maria Kleppe,

Memorial Sloan Kettering

Cancer Center, USA

*Correspondence:

Philippe Krebs

philippe.krebs@pathology.unibe.ch

Specialty section:

This article was submitted

to Inflammation,

a section of the journal

Frontiers in Immunology

Received: 05 November 2016

Accepted: 21 December 2016

Published: 09 January 2017

Citation:

Wasmer MH and Krebs P (2017) The

Role of IL-33-Dependent

Inflammation in the Tumor

Microenvironment.

Front. Immunol. 7:682.

doi: 10.3389/fimmu.2016.00682 we will present the current knowledge on the role of IL-33 in the microenvironment of different tumors. We will highlight which cells produce and which cells are activated by IL-33 in cancer. Furthermore, we will explain how IL-33 modulates the tumor-associated inflammatory microenvironment to restrain or promote tumorigenesis. Finally, we will discuss the issues to be addressed first before potentially targeting the IL-33 pathway for cancer therapy.

Keywords: cancer, inflammation, tumor microenvironment, interleukin-33, therapy

\section{INTRODUCTION}

Cancer is a heterogeneous disease and represents one of the leading causes of death worldwide. The process generally underlying cancer development was described as the "hallmarks" of cancer $(1,2)$. These hallmarks include self-sufficient proliferation, insensitivity to antiapoptotic signals, evasion of apoptosis, unlimited replication, maintenance of vascularization, and ability for invasion and metastasis. The so-called tumor microenvironment is also important for tumorigenesis, which supports the hallmarks of cancer. The concept of the tumor microenvironment implies that cancer cells alone are not able to manifest the disease but rather involve resident non-malignant cells or recruit them to participate to tumor development. The interactions between the cancer cells and

\footnotetext{
Abbreviations: AOM, azoxymethane; $\mathrm{BM}$, bone marrow; DC(s), dendritic cell(s); CAC, colitis-associated (colorectal) cancer; $\mathrm{CAF}(\mathrm{s})$, cancer-associated fibroblast(s); CCA, cholangiocarcinoma; $\mathrm{CDC}(\mathrm{s})$, conventional dendritic cell(s); CRC, colorectal cancer; CTL(s), cytotoxic T lymphocytes; DSS, dextran sodium sulfate; EGF, epidermal growth factor; EGFR, epidermal growth factor receptor; HCC, hepatocellular carcinoma; HNSCC, head and neck squamous cancer; HSPC(s), hematopoietic stem/progenitor cell(s); IBD, inflammatory bowel disease; IL, interleukin; ILC(s), innate lymphoid cell(s); MDSC(s), myeloid-derived suppressor cell(s); MMP, metalloprotease; NK, natural killer cells; NSCLC, non-small-cell lung cancer; pDC(s), plasmacytoid dendritic cell(s); PDGF, platelet-derived growth factor; $\mathrm{SST} 2$, soluble form of ST2; TNF, tumor necrosis factor; $\mathrm{T}_{\text {reg(s) }}$, regulatory T cell(s); VEGF, vascular endothelial growth factor; WT, wild type.
} 
their supporting stroma result in the formation of tumors and local invasions, metastasis, or vascular niches promoting malignancies (3). The tumor microenvironment consists of immune cells, endothelial cells, pericytes, fibroblasts, and smooth muscle cells $(4,5)$.

In addition to the occurrence of somatic "driver" mutations in transformed cells, long-term exposure to various environmental stresses, and certain diets may contribute to tumor development (6). Meanwhile, it is also widely accepted that inflammation has an important impact on tumorigenesis (4). The developing tumor itself can promote antitumor immune responses, which is mainly executed by cytotoxic T lymphocytes (CTLs), natural killer cells (NK), but also T helper 1 cells. However, local mechanisms of immune suppression specific to the tumor may blunt these tumor-infiltrating immune effectors (7-9). In addition, inflammatory stimuli may also exert a pro-tumorigenic action. Indeed, about $15 \%$ of malignancies are associated with microbes and a subsequent state of chronic inflammation $(10,11)$. Helicobacter pylori, human papillomavirus, hepatitis virus $\mathrm{B}$ and $\mathrm{C}$, as well as cytomegalovirus and Epstein-Barr virus have been related to gastric cancer, cervical cancer, hepatocellular carcinoma (HCC), and hematologic malignancies, respectively. Patients suffering from inflammatory bowel diseases (IBDs) have an increased risk of developing colorectal carcinomas $(12,13)$. Therefore, immune cells and inflammatory mediators are important components of the local environment of tumors (14).

Cytokines are central mediators of the interaction between cells in the inflammatory tumor microenvironment (15). Interleukin-33 (IL-33) is a member of the IL-1 family of cytokines. In contrast to other IL-1 family members like IL-1 $\beta$ and IL-18, IL-33 is inactivated upon caspase cleavage $(16,17)$. While fulllength IL-33 is already biologically active, its activity is enhanced $\sim 10$-fold upon cleavage by neutrophil serine proteases cathepsin $\mathrm{G}$ and elastase (18). Full-length IL-33 is mainly expressed by epithelial and endothelial cells, where it is stored and bound to the chromatin in the nucleus $(19,20)$. IL-33 may exert a dual function, as damage-associated molecular pattern (DAMP) and cytokine (21), or as nuclear factor modulating gene expression (22). Full-length IL-33 acts as "alarmin" if released extracellularly, subsequent to cell stress or damage. Soluble IL-33 binds to its receptor, a heterodimeric complex comprising IL-1RL1/ST2 (which is encoded by IL1RL1) and IL-1 receptor accessory protein (which is encoded by IL1RAP). IL-33/ST2 signaling is transduced via recruitment of MyD88 and IL-1 receptor-associated kinase-4 (IRAK-4), downstream adaptor proteins shared with other IL-1 family members and with most Toll-like receptors (TLRs) (Figure 1). In addition, a soluble form of ST2 (sST2) exists, which is produced by alternative promoter usage, $3^{\prime}$ processing or differential splicing and that may function as a decoy receptor for IL-33 (19, 23-25). IL-33 is primarily known as a driver of type-2 immune responses, triggering the release of Th2 cytokines and thereby promoting allergic reactions (26). Moreover, IL-33 supports tissue repair by coordinating the action of innate lymphoid cells (ILCs) and regulatory T cells ( $\left.\mathrm{T}_{\text {regs }}\right)(27-30)$. Yet, IL-33 may also be involved in pathologic wound repair and fibrosis (31-34). Finally, recent findings have revealed an important contribution

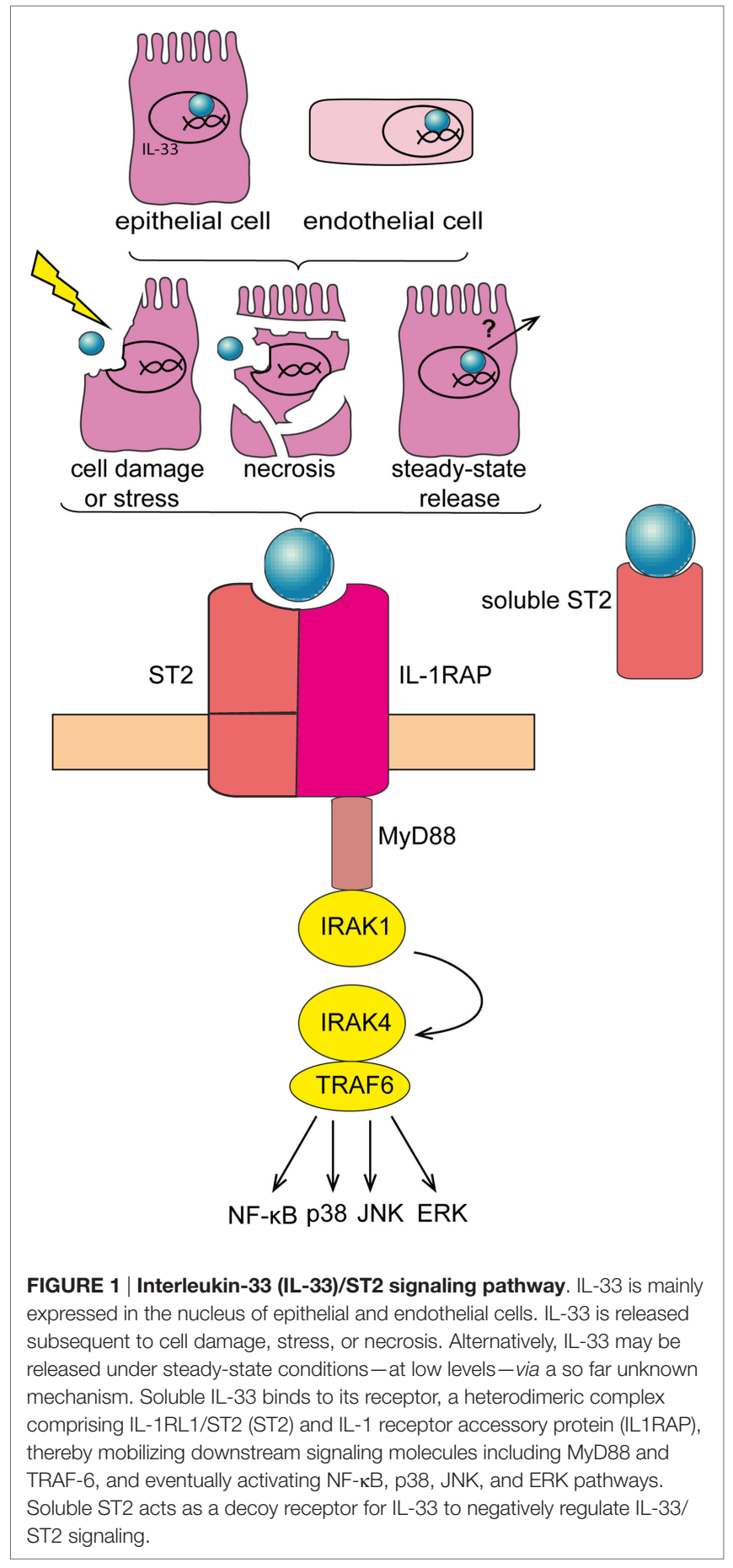

of IL-33 to several cancers, where it may exert pro and-less frequently-anti-tumorigenic functions (35).

Here, we review the current knowledge about the role of IL-33 in the microenvironment of different types of tumors. Each cancer type is presented according to the following scheme: (1) short introduction to the specific cancer type; (2) net effect of IL-33/ST2 signaling for tumorigenesis; (3) origin of IL-33- and ST2-expressing cells in the tumor stroma of a particular cancer type; (4) mechanisms of action of IL-33; and (5) 
therapeutic opportunities. Furthermore, we discuss the major issues which we believe should be investigated in the future to improve our understanding of the role of IL-33 for tumor initiation/progression, toward the development of therapeutic strategies.

\section{MAIN REVIEW TEXT}

\section{IL-33 in Head and Neck Squamous Cancer (HNSCC)}

Head and neck squamous cancer represents one of the six leading cancer types worldwide and it arises in the oropharynx, larynx, oral cavity, and hypopharynx. Major risk factors for the development of HNSCC are alcohol consumption and tobacco smoke. However, infection with human papillomavirus (HPV) can also promote tumor development (36).

The tumor microenvironment appears to strongly contribute to HNSCC development. Cancer-associated fibroblasts (CAFs) are the most critical cells in the HNSCC microenvironment, which promote tumor cell proliferation, invasion, and metastatic potential. Therefore, CAFs determine HNSCC tumor aggressiveness. These CAFs release IL-33, which induces epithelial-tomesenchymal transition of cancer cells, thereby supporting their ability for migration and invasion. Furthermore, IL-33 induces IL33 gene expression in HNSCC cells via a positive feedback mechanism. Increased IL33 expression in CAFs and in tumor cells is associated with low patient survival (37). In patients with squamous cell carcinoma of the tongue, high expression of IL-33 or ST2 is indicative of worse prognosis. Increased IL-33 levels in these tumors also correlate with microvessels in the stroma (38).

While these data suggest that IL-33 blockade may be beneficial for HNSCC patients, further investigations are required to define downstream key factors dependent on IL-33 for the development of HNSCC. In particular, in vivo experiments should be performed to validate these initial data.

\section{IL-33 in Non-Small-Cell Lung Cancer (NSCLC)}

Non-small-cell lung cancer is the most common type of lung cancers, representing more than $85 \%$ of all lung cancers. NSCLC has a predicted 5-year survival rate of $15.9 \%$. Although the prognosis for NSCLC has only marginally changed the past years, understanding of the cellular and molecular mechanisms underlying the disease has greatly improved (39).

While many studies have shown a critical role of the IL-33/ ST2 signaling in inflammatory lung disease, including respiratory allergy, asthma, and chronic obstructive lung disease (19, 40-42), few have investigated the contribution of this pathway to lung cancer. In NSCLC patients, expression of IL33 and IL1RL1 was found to be increased in tumor tissue compared to adjacent non-tumor tissue, and this expression was associated with disease clinical stage (43). However, another study reports downregulation of IL33 and IL1RLI in human lung cancer tissue and cells, compared to normal tissue and cells. Furthermore, the authors found that IL33 and ILIRL1 transcript levels were inversely correlated with stages of human lung cancers and overall survival. Accordingly, ST2 protein was expressed in low-metastatic, but not in highmetastatic Lewis lung carcinoma (3LL) cells (44).

Mechanistically, in vitro stimulation with IL-33 or overexpression of IL33 in primary NSCLC cells enhanced their growth and metastasis after transfer into immunodeficient mice. Inversely, shRNA-mediated knockdown of IL33 in primary NSCLC cells limited their proliferation and invasion capacity in vivo. Corresponding results were obtained by overexpressing or downregulating IL1RL1 in NSCLC cells, thereby showing that the IL-33-driven tumor progression in this model relies on ST2. In addition, engagement of IL-33/ST2 signaling in NSCLC cells was found to increase the membrane expression of glucose transporter 1 (GLUT1) and thereby enhance their glucose uptake and lactate production. Finally, knockdown of SLC2A1/GLUT1 in NSCLC cells diminished their IL-33mediated proliferation as well as their metastatic potential, in vitro (43).

Yet, IL-33 may also trigger death of ST2-expressing lung tumor cells under conditions mimicking the tumor environment in vitro, including upon nutrient depletion or under hypoxic/ anoxic conditions. This mechanism may possibly select for more malignant, ST2-negative cancer cells (44).

One can only speculate on the reason for the controversial findings in these two studies. Patient cohorts and cohort size were different in the two investigations. Moreover, no information was provided on the therapeutic status of the analyzed patient samples. Indeed, radiotherapy, alone or in combination with chemotherapy, belongs to the standard treatment of NSCLC (45), which can lead to a rapid increase in the expression of IL-33 protein in tissues (46). Thus, careful evaluation of patient therapeutic history is key for the study of IL-33 signaling in human samples. Finally, while one study describes the use of lung cancer cell lines, primary NSCLC cells were used in the other report, which makes a direct comparison difficult.

Therefore, additional studies are necessary to clarify the contribution of IL-33/ST2 signaling to lung cancer, in particular to NSCLC.

\section{IL-33 in Breast Cancer}

Breast cancer is one of the major causes of cancer-related death among women worldwide (47). Distant metastasis to the lung, bones, liver, and brain are causal for the death of breast cancer patients (48). The immune system has an ambivalent role in breast cancer as it may either promote or prevent tumorigenesis. Tumor-infiltrating leukocytes in particular have a strong effect on breast cancer development. While NK cells and CTLs mediate an anti-tumorigenic response in the microenvironment of breast tumors, $\mathrm{T}_{\text {regs }}$ and myeloid-derived suppressor cells (MDSCs) act in an immunosuppressive fashion [reviewed in Ref. (49)].

Several studies point toward a pro-tumorigenic role of IL-33/ ST2 signaling in breast cancer. IL-33 and ST2 expression are elevated in human breast cancer tissue compared to normal breast tissue $(50,51)$. In breast cancer patients, serum levels of IL-33 and of its decoy receptor sST2 were enhanced compared to healthy controls. This positively correlated with the expression of 
vascular endothelial growth factor (VEGF), metalloprotease-11 (MMP-11), or platelet-derived growth factor-C, which are markers of poor prognosis in breast cancer (52).

Compared to wild-type (WT) controls, Il1rl1-deficiency led to delayed tumorigenesis in mice tested in the syngeneic $4 \mathrm{~T} 1$ breast cancer model. Moreover, after orthotopic injection of 4T1 cells, Il1rl1-deficient mice showed reduced metastatic potential to the lung and liver. This was caused by decreased tumor cell proliferation in Il1rl1-deficient mice. Accordingly, administration of IL-33 in this model enhanced tumor cell proliferation in WT mice, through an indirect effect of IL-33 on tumor cells $(53,54)$.

In the $4 \mathrm{~T} 1$ breast cancer model, IL-33 was expressed by CD45-positive leukocytes and tumor cells, while ST2 was mainly expressed on $\mathrm{T}_{\text {regs }}$ and type-2 ILCs (54). Furthermore, there were fewer MDSCs in tumor lesions of Il1rl1-deficient mice, while treatment with exogenous IL-33 promoted the accumulation of these suppressor cells in mammary tumors. MDSCs responded to IL-33 by increasing their production of immunosuppressive TGF- $\beta$ (54). These MDSCs may be recruited from peripheral lymphoid organs to the tumor lesions, where they trigger the generation of $\mathrm{CD}^{+}$FoxP3 $^{+} \mathrm{T}_{\text {regs }}$ (55). Indeed, the percentage of $\mathrm{CD}^{+}{ }^{+} \mathrm{FoxP}^{+} \mathrm{T}_{\text {regs }}$, especially the cells expressing ST2 and IL-10, was found to be enhanced within 4T1 mammary tumors.

In addition to these indirect pro-immunosuppressive mechanisms, IL-33 signaling appears to also blunt tumor surveillance in the murine 4T1 breast cancer model. Indeed, NK cells showed increased IFN- $\gamma$ production in $I l 1 r l 1^{-1-}$ mice injected with 4T1 breast cancer cells, which translated into improved antitumor immunity. Along the same line, administration of IL-33 reduced NK cell function via decreased expression of FasL or NKG2D and enhanced programed cell death protein 1 (PD-1) levels. IL-33 also altered the ratio of dendritic cell subsets in $4 \mathrm{~T} 1$ breast tumor lesions (54).

In other models, IL-33 also showed a direct action on malignant breast cells. Stimulation with IL-33 enhanced proliferation as well as colony formation and size of a ST2-expressing breast cancer cell line. This occurred via a mechanism involving MAP3K8 phosphorylation upon engagement of IL-33/ST2 signaling (51).

Together, these studies indicate that the IL-33/ST2 pathway promotes breast tumorigenesis both directly, via activation of cancer cells, and indirectly, via modulation of antitumor immunity. Thus, the IL-33/ST2 pathway may represent an interesting target for breast cancer therapy.

\section{IL-33 in Hepatocellular Carcinoma (HCC)}

Hepatocellular carcinoma is one of the most prevalent cancers and it represents a prominent cause of mortality. Individuals with advanced fibrosis, cirrhosis, and hepatitis B are predisposed to HCC development. Patients with chronic hepatitis B and C infections are most commonly affected. The pathogenesis of HCC is a multistep and complex process, wherein angiogenesis plays an important role $(56,57)$.

Immuno-histochemical analysis revealed an increase in IL-33-positive tissue in HCC compared to normal liver tissue. In addition, IL-33 serum levels were higher in pre- and postoperative serum samples from HCC patients compared with normal healthy controls (58). However, a different research group found no difference in IL-33 serum levels in HCC compared to liver cirrhosis patients and healthy controls, although levels of sST2 were significantly elevated in their liver cirrhosis and HCC patient groups compared to healthy controls. In HCC patients, serum sST2 levels correlated with overall survival (59).

Yet another study reports reduced levels of IL-33 protein in HCC compared to normal liver, hepatitis, and cirrhosis tissues. Moreover, while IL-33 was observed both in the nucleus and, to a lesser extent, in the cytoplasm of hepatocytes in normal liver tissue, HCC showed only cytoplasmic IL-33 staining. IL-33 expression was negatively associated with HCC histological grade, but not with other parameters including lymph node metastasis. Together, this suggests that cytoplasmic/non-nuclear IL-33 might play a role in HCC development (60).

Although the mechanisms by which IL-33/ST2 signaling may contribute to HCC are still elusive, tumor-infiltrating, IL-33producing effector-memory $\mathrm{CD}^{+} \mathrm{T}$ cells have been observed in resected HCC tissue, which are associated with prolonged patient survival (61).

\section{IL-33 in Cholangiocarcinoma (CCA)}

Cholangiocarcinoma is a malignant neoplasm of the biliary-duct system that represents the second most common primary hepatic malignancy (62). Parasite infections, primary sclerosing cholangitis, biliary-duct cysts, hepatolithiasis, and toxins are known risk factors of this type of cancer (62). Moreover, CCA is also associated with chronic inflammation.

Interleukin-33 has a promoting role for CCA. In a murine model of CCA based on biliary epithelium transduction of constitutively active AKT and Yes-associated protein (YAP) together with bile duct ligation, administration of IL-33 increased biliary tumorigenesis (63). Mechanistically, ST2 protein was expressed in cancer cells and in CAFs, and IL-33 enhanced tumorigenesis through an increase of IL- 6 expression in tumor tissue. Moreover, IL-6 was able to substitute for IL-33 in this model (63). IL-6 triggers survival and mitogenic signals in CCA cells, in an autocrine or paracrine fashion $(64,65)$. Alternatively, administration of IL-33 to mice was found to enhance cholangiocyte proliferation, via a mechanism involving an increase in the number of IL-13producing type-2 ILCs. Activation of this IL-33/ILC2/IL-13 axis in animals with constitutive activation of AKT and YAP in bile ducts induced CCA with liver metastases (66).

Additional in vivo experiments for instance using blocking antibodies are necessary to evaluate the relevance of the IL-33/ IL-6 or IL-33/IL-13 axis as therapeutic targets in CCA.

\section{IL-33 in Gastric Cancer}

Gastric cancer represents the fourth most common type of cancer and is the second leading cause of cancer-mediated death in the world (67). The 5-year overall survival of gastric cancer patients is only around 20\% (68). Major risks for the development of gastric cancer are dietary factors, $H$. pylori infections, gastro-esophageal reflux disease, and obesity [reviewed in Ref. (68)]. Inflammation is an important contributor to gastric tumorigenesis, which is exemplified by the well-studied pro-tumorigenic role of $H$. pylori for this cancer. Indeed, bacterial virulence factors of $H$. pylori and 
pathogen interaction with the host immune system result in a chronic inflammation that promotes tumorigenesis $(69,70)$.

Interleukin-33 appears to exert a pro-tumorigenic function in gastric cancer. Human gastric cancer cell lines stimulated with IL-33 showed a dose-dependent increase in cancer cell invasion and migration. These effects were abrogated by knocking-down IL1RL1. Engagement of IL-33/ST2 signaling in these gastric cancer cell lines activated ERK1/2 (71), a pathway known to be important for tumor invasion and metastasis (72). Moreover, IL-33 also triggered gastric cancer cells to secrete IL-6 and MMP-3 (71), factors with established pro-tumorigenic properties $(73,74)$.

Still, additional studies on human gastric cancer tissue and in vivo experiments in mice are required to further assess the function of IL-33 for gastric cancer development and progression.

\section{IL-33 in Colorectal Cancer (CRC)}

Colorectal cancer represents one of the most common human cancer types, that is fatal in a considerable number of cases (75). CRC development is a multistep process that follows the adenoma-carcinoma sequence as a consequence of the accumulation of alterations in key oncogenes and tumor suppressor genes involved in the Wnt/ $\beta$-catenin-, KRAS-, MYC-, MAPK-, TGF$\beta /$ bone morphogenetic protein-signaling pathways-among others-and TP53 (76-78). Chronic inflammation strongly promotes intestinal tumorigenesis (4), which is also illustrated by the fact that patients suffering from IBD have a higher risk to develop CRC $(79,80)$. In addition, several cytokines and inflammatory mediators have been shown to be associated with or to promote intestinal tumorigenesis (81).

While most studies have shown a pro-tumorigenic role of IL-33/ST2 signaling in CRC, recent data suggesting a protective role have also been published. We and others found increased levels of IL33 and IL1RL1 expression, both on the transcript and protein level, in adenoma and low grade adenocarcinoma of CRC patients, compared to adjacent normal tissue and high grade tumors $(82,83)$. Similarly, IL33 transcript levels were found to be higher in stage I-III CRC compared to adjacent normal colonic tissue. However, IL33 expression was lower in stage IV CRC than in stage I-III intestinal tumors (84). In contrast, another study reports progressively increasing levels of IL33 and IL1RL1 transcript from low to high grade and stage of human CRC (85).

In animal models, Il33 and Il1rl1 levels are elevated in adenomatous polyps of $A p c^{\mathrm{Min} /+}$ mice. In this model of CRC, Il33 deficiency is associated with decreased growth of intestinal polyps (86). Similarly, in the azoxymethane (AOM)/dextran sodium sulfate (DSS) model of colitis-associated CRC (CAC), we found that IL-33/ST2 signaling promotes tumorigenesis. Indeed, $\mathrm{IlIrl1}^{-/-}$ mice treated with AOM/DSS showed delayed CAC development, fewer/smaller tumors and lesions of lower grade, compared to WT controls. Experiments using bone marrow (BM) chimeric mice indicated that IL-33/ST2 signaling was engaged on both the radio-resistant and the radio-sensitive compartment (83). In a different model of CRC, syngeneic MC-38 colon carcinoma cells injected into the cecum of recipient mice showed enhanced growth and liver metastasis when overexpressing IL-33 (84).
Stimulation of human primary CRC cells with exogenous IL-33 resulted in a dose-dependent increase in their invasive potential. In addition, IL-33 overexpression in these CRC cells resulted in an enhanced invasion, a mechanism dependent on signaling through ST2. These in vitro findings were confirmed by challenging nude mice with metastatic SW620 cells. Overexpressing IL33 in SW620 cells injected subcutaneously enhanced their growth, metastasis, and reduced the survival of recipient nude mice, while downregulating IL33 had an opposite effect (85).

In human and murine CRC tissue, IL-33 is predominantly expressed by epithelial cells but also in endothelial cells and myofibroblasts. ST2 is mainly expressed on transformed epithelial cells, endothelial cells, myofibroblasts, and infiltrating immune cells $(82,83,86,87)$.

Mechanistically, IL-33 enhances the recruitment of $\mathrm{CD} 11 \mathrm{~b}^{+} \mathrm{F} 4 / 80^{+}$macrophages and $\mathrm{CD} 11 \mathrm{~b}^{+} \mathrm{Gr}-1^{+}$MDSCs to CRC tumors. IL-33 also stimulates the secretion of S100A8/9 (a DAMP) and VEGF from these cell populations to support tumor angiogenesis and metastasis (84).

Several studies have reported an accumulation of mast cells in human and mouse intestinal adenomas, which promote polyposis in Apc mutant mouse models via stimulation of angiogenesis, modulation of $\mathrm{T}_{\text {reg }}$ function, and mobilization of MDSCs within the tumor microenvironment (88-90). Along these lines, Il33-deficient $A p c^{\mathrm{Min} /+}$ mice showed reduced accumulation of ST2-expressing mast cells in their polyps, compared to $A p c^{\mathrm{Min} /+}$ mice expressing Il33. In the same model, abrogation of IL-33/ST2 signaling was associated with reduced expression of proteases and cytokines known to promote polyposis (86).

Stimulation of primary human CRC cells with IL-33 resulted in an increased secretion of IL-6, CXCR4, MMP-2, and MMP-9 (85), which have all been involved in CRC metastasis (91-95). $A p c^{M i n /+}$ mice deficient in Il33 show reduced transcript levels of $I l 4$ and Il6, which drive CRC development $(81,86)$. In addition, engagement of IL-33/ST2 signaling on radio-resistant cells decreases the integrity of the intestinal barrier and enables translocation of microbial products to the circulation. This was associated with enhanced systemic levels of pro-tumorigenic IL-6. Furthermore, hematopoietic cells isolated from the vicinity of CAC lesions and stimulated with exogenous IL-33 showed upregulated Il6 transcript levels. Therefore, the IL-33/ST2 axis contributes to colorectal tumorigenesis partly via increased production of IL-6 (83).

Epidermal growth factor (EGF) appears to regulate Il33 expression in intestinal epithelial cells. In tumors of AOM/DSSchallenged mice treated with gefitinib, an inhibitor of epidermal growth factor receptor, Il33 transcript levels were decreased, compared to untreated controls. This correlated with fewer and smaller tumors in this model. EGF stimulation of an intestinal epithelial cell line increased its expression of ST2 and intracellular IL-33 (87). This suggests a link between EGF and the IL-33/ST2 signaling axis and may provide a target for the treatment of CRC, although this requires further investigation.

In contrast to the above-presented findings, two recent studies reported an anti-tumorigenic role of IL-33/ST2 signaling for intestinal tumorigenesis. In a first report, expression of transmembrane ST2 was found to be lower in human CRC 
compared to adjacent, non-tumor tissue, and it progressively decreased during tumor progression from Stage I to Stage IV CRC. While shRNA-mediated knockdown of Illrl1 did not alter the proliferation or migration of CT26 CRC cells in vitro, these cells developed larger tumors when injected into the flanks of immunocompetent recipient mice. This correlated with a reduction of macrophage recruitment to the tumor tissue, likely due to diminished CCL2 production by tumor cells with abrogated IL-33/ST2 signaling (96). In a second report, IL-33 was shown to promote IgA production, thereby preventing microbial dysbiosis and IL-1 $\alpha$-dependent inflammation in the intestine. Upon AOM/DSS treatment of Il33-deficient mice, this translated in augmented secretion of inflammatory cytokines as well as tumors of increased number, size, and grade, compared to WT mice (97). However, it is currently not known whether IL-33 fulfills a similar function in the human intestine, where manipulation of the microbiota may represent a therapeutic strategy for the treatment of CRC, independently of IL-33 (81).

Taken together, the ambivalent role of IL-33/ST2 signaling for CRC tumorigenesis in mouse models makes it difficult to assess this pathway as a possible target for CRC therapy in humans. It seems important to compare the different murine models presented above side-by-side. Moreover, additional experiments should be performed that involve blockade of the IL-33/ST2 pathway at different stages of CRC progression. Also, chemotherapy may differently affect ST2 and IL-33 levels in CRC patients (96), which should be considered in the design of future human studies on these molecules.

\section{IL-33 in Myeloproliferative Neoplasms (MPNs)}

Myeloproliferative neoplasms constitute a group of chronic hematologic malignancies which are characterized by an abnormal proliferation of myeloid cells (98). They are classified as BCR-ABL1-positive MPN, for chronic myeloid leukemia (CML), or BCR-ABL1-negative MPNs, which mainly comprise polycythemia vera, essential thrombocythemia, and primary myelofibrosis $(98,99)$. Most cases of BCR-ABL-negative MPNs present a mutation in a molecule involved in JAK/STAT signaling (100). As a consequence of these diverse genetic aberrations, cytokine signaling is dysregulated in both classes of MPNs (98).

Interleukin-33/ST2 signaling supports the development of both BCR-ABL1-positive and -negative MPNs. Increased levels of nuclear IL-33 protein are present in trephine biopsies of BCRABL1-negative MPN patients, and high amounts of circulating soluble ST2 were detected in the plasma from CML patients, compared to controls. Furthermore, ST2 is upregulated on the surface of $\mathrm{CD}_{3} 4^{+}$hematopoietic stem/progenitor cells (HSPCs) of BCR-ABL1-positive and -negative MPN patients, compared to healthy donors $(101,102)$. Addition of exogenous IL-33 increased the colony forming potential of $\mathrm{CD} 34^{+}$HSPCs of MPN patients (102).

In mouse models, we found that IL-33 supports MPN-like disease and myeloproliferation in mice deficient in Inppd5 or in irradiated recipients transfused with BM cells transgenic for human $J A K 2^{\mathrm{V} 617 \mathrm{~F}}$, one of the most common driver mutations in
MPN patients (102). CD34 ${ }^{+}$HSPCs from CML patients engrafted better in immunodeficient mice after pre-treatment with IL-33, and BCR-ABL-expressing BM cells showed reduced ability to induce CML-like disease when transplanted into Il33-deficient versus Il33-competent recipients (101).

Interleukin-33 is expressed in radio-resistant cells, including endothelial cells, in the BM. ST2 expression in the BM is mainly restricted to endothelial, mesenchymal, and early myeloid cells. Importantly, ST2 was not detected on murine HSPCs. The IL-33/ST2 pathway in the BM can be activated both in stromal/ non-hematopoietic and in hematopoietic cells. Engagement of ST2 on these cells leads to secretion of cytokines known to promote the development and proliferation of myeloid cells, including IL-6, GM-CSF, G-CSF, and IL-3 (102). Since human $\mathrm{CD}_{3}{ }^{+}$HSPCs express ST2, they are able to directly respond to IL-33 stimulation in vitro, which induces cytokine production and subsequent cell proliferation $(101,102)$. These cytokines, in turn, activate the STAT5 pathway and can confer resistance to imatinib mesylate, a specific kinase inhibitor of the BCR-ABL1 fusion protein (101).

While these data suggest a potential therapeutic benefit in blocking IL-33/ST2 signaling in MPNs, additional experiments should first assess the role of this pathway for disease progression and drug resistance in MPN patients.

\section{IL-33 As Immune Adjuvant for Vaccine Therapy}

Except for a few particular examples presented above, IL-33 has mainly a pro-tumorigenic function for cancer development (96, 103). However, IL-33 may also function as an immune adjuvant for antitumor immune response. Indeed, IL-33 has been shown to promote potent cancer-specific effector and memory $\mathrm{T}$ cell immunity when used as an adjuvant for DNA vaccination in mice (104). This is in line with findings indicating that IL-33 increases the numbers of $\mathrm{CD}^{+} \mathrm{T}$ cells and NK cell-producing IFN- $\gamma$ in transgenic B16 tumors overexpressing IL-33, thereby mediating a microenvironment favoring tumor rejection. However, IL-33 also promoted the accumulation of immunosuppressive ST2-expressing $\mathrm{T}_{\text {regs }}$ in this model (103).

Interestingly, aluminum-based adjuvants (alum) induce cell necrosis that leads to extracellular release of IL-33 and the subsequent induction of several IL-33-dependent inflammatory cytokines. In addition, IL-33 injected together with the NP-CGG model antigen increased NP-specific IgM titers in the primary response and T cell-dependent NP-specific IgG1 titers after antigen boost. This indicates that IL-33 can induce robust antigenspecific antibody responses (105). IL-33 was also reported to reduce the accumulation of MDSCs in the spleen and tumor microenvironment, and to decrease the immunosuppressive activity of these cells, which limited tumor growth (106).

Together, these findings indicate the possible use of IL-33 as an immune adjuvant. Yet, there may be some challenges in applying IL-33 for immunomodulation or vaccination, as high levels of IL-33 may lead to lethal inflammatory disease in mice $(107,108)$. Therefore, it might be difficult to find the right dose of IL-33 to support the desired antitumor-specific immune response while 
avoiding exacerbated inflammation. This may restrict the possibility of using IL-33 in a vaccine setting.

\section{IL-33 As Tumor Biomarker or Therapeutic Target}

As presented above, IL-33 contributes to the modulation of the tumor environment by promoting the recruitment of pro-tumorigenic immune cells or the secretion of tumorigenic cytokines. However, IL-33 can be detected not only in the tumor environment, but also in the serum of cancer patients. For instance, IL-33 levels are increased in the serum of lung and gastric cancer patients and correlate with disease stage, suggesting that IL-33 may be a negative prognostic marker for these types of cancer $(109,110)$. Moreover, expression levels of IL33 and ST2 correlate with tumor grade and inferior survival of glioblastoma patients (111). However, IL-33 expression indicates favorable prognosis in patients with malignant salivary gland tumors (112). In addition, loss of IL33 expression may also promote tumor escape in patients with metastatic prostate carcinomas or kidney renal clear cell carcinomas, via down-modulation of genes involved in antigen processing and of major histocompatibility complex (MHC-I/HLA)-genes (113). Therefore, IL-33 and ST2 differently contribute to tumorigenesis depending on the nature of the malignant tissue.

For breast cancer, IL-33 and sST2 may also serve as noninvasive diagnostic marker, as these two proteins are upregulated in the serum of patients [(52) and see also the paragraph on breast cancer above]. However, IL-33 is upregulated in different types of inflammatory diseases (114-116) and cancers $(111,112)$, and this lack of specificity may prevent its use as a biomarker in the daily clinic diagnostic. Furthermore, while high levels of IL-33 in absence of common markers of inflammation may indicate the presence of cancer, it would not indicate the identity of the cancerous tissue, and more specific markers would be additionally required for diagnostics. Another level of complexity comes from the observation that the IL-33/ST2 pathway appears to be differently regulated during the progression of distinct types of cancers, as mentioned just above.

While cytokine blockade is currently applied for the treatment of inflammatory disorders, including for instance the use of antitumor necrosis factor- $\alpha$ monoclonal antibodies to treat ulcerative colitis and Crohn's disease, it remains to be investigated whether a blockade of the IL-33/ST2 pathway may represent a valid approach for the therapy of established IL-33-dependent tumors. Experimental evidences are currently lacking that clearly indicate the suitability of such an approach. Alternatively, IL-33 blockade might be applied in combination with other (immuno) therapies. As IL-33 mainly acts as an amplifier of inflammation (117), targeting IL-33 may suppress the pro-tumorigenic inflammation in the tumor stroma, therefore improving the treatment with conventional therapies. For instance, combination of imatinib and IL-33 blockade in CML may allow elimination of cytokine-dependent malignant stem cells (118) or prevent the emergence of drug resistance (101). Along these lines, combined administration of IL-33 and PD-1 blockade was recently shown to improve the survival of mice suffering from acute myeloid leukemia (119).

\section{CONCLUSION AND DISCUSSION}

The tumor microenvironment represents a critical incubator for tumor development, local invasion, and metastasis (3). This environment can be modulated by different factors including pro- or anti-tumorigenic cytokines (15). The alarmin IL-33, an amplifier of innate immune response (117), has been shown to contribute to different types of inflammatory diseases and more recently to modulate tumorigenesis (Figure 2) (35, 42). Several investigations using patient-derived material, in vitro approaches, or in vivo models have uncovered a differential role of the IL-33/ST2 pathway in the tumor microenvironment, for tumor initiation, development, and resistance to therapy (Table 1). While IL-33 has generally a pro-tumorigenic function in various cancers, for some cancer types the findings generated so far are controversial. We discuss below possible reasons for these discrepancies and how they may be possibly addressed or resolved.

\section{Different IL-33- and ST2-Expressing Cell Types in the Tumor Environment}

Several of the expression studies presented above analyzed whole tumor tissues, without distinction of the different IL-33- and ST2expressing cell types in the tumor microenvironment. However, not only transformed cells, but also infiltrating immune cells, endothelial cells, or myofibroblasts may express IL-33 or ST2 in the tumor stroma $(54,83,86,102,120)$. Therefore, the presence or contribution of these non-cancerous cells should be separately evaluated for future correlative or functional studies.

The relevance of IL-33- and ST2-expressing non-cancerous cells to tumorigenesis may also explain the contradictory outcomes from distinct animal models. Indeed, xenograft studies are not suitable to address the contribution of stromal cellspecific IL-33/ST2 signaling to tumorigenesis. While there is a $55 \%$ homology (19) and a 66\% identity at the amino-acid level between human and murine IL-33 and ST2, respectively, it is not known whether these molecules can cross-react between the two species. Moreover, immune cells can engage ST2 upon IL-33 binding, whose contribution cannot be assessed using immunocompromised animals as recipients of xenografts. Finally, for certain types of cancers, heterotopic models may not properly address the role of the physiologic tumor microenvironment. This holds true in particular for CRC, since IL-33 can control dysbiosis in the intestine, which in turn impacts on colon tumorigenesis (97) - a parameter likely omitted by studies involving subcutaneous application of CRC cells. Therefore, these limitations shall be taken into account, especially when evaluating the clinical relevance of the different findings.

\section{Spatiotemporal Contribution of IL-33 and ST2 to Tumorigenesis}

Interleukin-33 may differently contribute to tumorigenesis in dependence on where it is available. As presented above, local IL-33 in the tumor microenvironment can directly trigger cancer or stromal cells. However, IL-33, in particular when given exogenously, may drain to the lymph nodes, where it can promote antitumor responses-as shown in several immune adjuvant vaccine studies (see the above paragraph on IL-33 as immune 


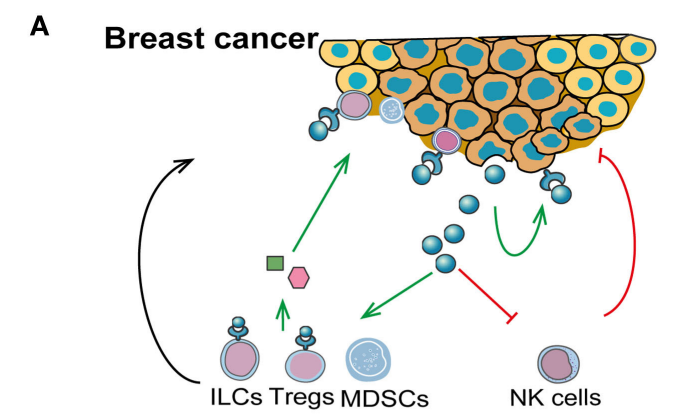

C Colon cancer

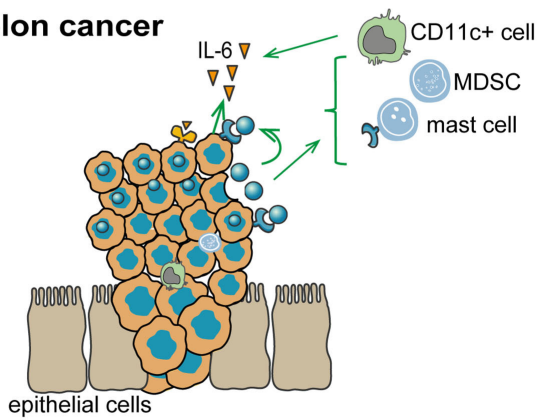

epithelial cells

\section{B Gastric cancer}

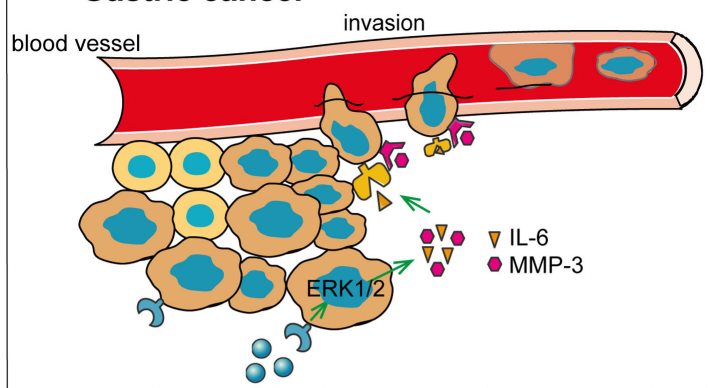

D Myeloproliferative neoplasm

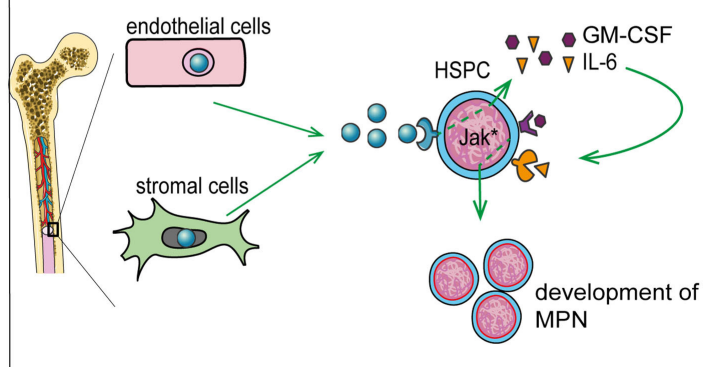

$$
\begin{aligned}
& \text { normal cell } \\
& \text { tumor cell } \\
& \rightarrow \text { recruitment } \\
& \rightarrow \text { activation } \\
& \longrightarrow \text { blockade } \\
& \text { IL-33 } \\
& \& \mathrm{ST} 2 \text { receptor } \\
& \square \text { cytokines }
\end{aligned}
$$

FIGURE 2 | Role of interleukin-33 (IL-33) in the tumor microenvironment. (A) In breast cancer (mouse 4T1 breast cancer model), IL-33 is released by tumor cells and acts in an autocrine/paracrine manner. In addition, IL-33 promotes the recruitment of immunosuppressive cells and inhibits the function of antitumor cytotoxic natural killer cells (NK). (B) In gastric cancer, IL-33 may promote vessel invasion of tumor cells by stimulating the secretion of IL-6 and MMP-3 through activation of the ERK pathway. (C) In colorectal cancer, IL-33 supports the recruitment to the tumor environment of pro-tumorigenic immune cells, including mast cells and myeloid-derived suppressor cells (MDSCs). In addition, IL-33 promotes the secretion of pro-tumorigenic IL-6 by leukocytes in the tumor vicinity, which are possibly CD11 $\mathrm{C}^{+}$dendritic cells. (D) In patients with myeloproliferative neoplasms, IL-33 is released by bone marrow stromal and endothelial cells, and it engages ST2 on CD34+ hematopoietic stem/progenitor cells, thereby promoting their secretion of IL-6 and GM-CSF. These cytokines, in turn, stimulate in an auto/paracrine manner the uncontrolled proliferation of the malignant clone (due to its defect in JAK/STAT signaling).

adjuvant). While this has still to be demonstrated, systemic IL-33 may also possibly keep ST2-expressing immunosuppressive cells at sites distant from (IL-33-expressing) tumors, thereby "distracting" them from their pro-tumorigenic role. Indeed, in vivo IL-33 administration can restrict the accumulation of MDSCs in the tumor microenvironment (106).

Finally, IL-33/ST2 signaling may contribute to different stages of tumorigenesis, including tumor growth or metastasis, and additional genetic tools are needed to systematically dissect the role of this pathway at specific time points of cancer development.

\section{Regulation of IL-33 Release-Role of IL-33 As a Cytokine}

As IL-33 may become upregulated in different types of cells upon malignant transformation, its mere presence in tumors should not always imply engagement of ST2-dependent signaling, which may also explain conflicting findings across studies. IL-33 first needs to be released extracellularly before binding to its receptor.
However, the exact mechanisms for the regulation and release of IL-33 are still elusive, and they may vary between distinct experimental settings or models. Indeed, in addition to cell damage/necrosis-dependent release of IL-33, IL-33 may also become actively released. Stress conditions associated with increased extracellular adenosine triphosphate (ATP) (a DAMP) may trigger IL-33 secretion after activation of purinergic receptor P2Y2R signaling in live cells $(40,121)$. Moreover, alternative splicingmediated deletion of exon 3 and 4 of IL33 transcripts confers cytoplasmic localization of IL-33 proteins, which facilitates its extracellular secretion from airway epithelial cells of asthmatic patients. Importantly, this isoform of IL-33 was shown to retain its ability to signal through ST2 (122). Thus, it is conceivable that such IL-33 isoforms are also preferentially produced by tumor cells (or cells in the tumor microenvironment), a hypothesis that remains to be addressed. Detectable amounts of IL-33 can be measured in the serum of healthy patients (123) and naïve mice (102) suggesting that IL-33 is released and circulates even under 
TABLE 1 | Interleukin-33 (IL-33) and ST2 levels and contribution in different cancers.

\begin{tabular}{|c|c|c|c|c|c|c|c|c|}
\hline \multirow[b]{3}{*}{ Type of cancer } & & \multicolumn{6}{|c|}{ Net effect of } & \multirow[b]{3}{*}{ Major references } \\
\hline & & \multicolumn{3}{|c|}{ IL-33 } & \multicolumn{3}{|c|}{ ST2 } & \\
\hline & & Expression & $\begin{array}{c}\text { Tumor } \\
\text { progression }\end{array}$ & Metastasis & Expression & $\begin{array}{c}\text { Tumor } \\
\text { progression }\end{array}$ & Metastasis & \\
\hline Head and neck squamous cancer & Human & + & + & & & & & $(37,38)$ \\
\hline \multirow[t]{2}{*}{ Non-small lung cancer } & Human & + & + & + & + & + & + & $(43)$ \\
\hline & & - & - & & - & - & & $(44)$ \\
\hline \multirow[t]{2}{*}{ Breast cancer } & Human & + & & & + & & & $(50,51)$ \\
\hline & Mouse & & + & & & + & + & $(53,54)$ \\
\hline Hepatocellular carcinoma & Human & + & + & & + & & & $(58,59)$ \\
\hline Cholangiocarcinoma & Mouse & & + & + & + & & & $(63,66)$ \\
\hline Gastric cancer & Human & & + & + & & + & + & $(71)$ \\
\hline \multirow[t]{4}{*}{ Colorectal cancer } & Human & + & + & + & + & + & & $(82,83,85)$ \\
\hline & & - & & & - & & & $(96)$ \\
\hline & Mouse & + & + & + & + & + & & $(83,84,86)$ \\
\hline & & & - & & & - & & $(96,97)$ \\
\hline \multirow[t]{2}{*}{ Myeloproliferative neoplasms } & Human & + & + & & + & & & $(101,102)$ \\
\hline & Mouse & & + & & & + & & $(102)$ \\
\hline
\end{tabular}

+, promoting effect; -, suppressing effect.

steady-state conditions (Figure 1). Thus, such basal level of IL-33 may also help amplify the inflammatory milieu in chronic inflammatory disorders, which have been shown to provide favorable conditions for the development of tumors (4). Therefore, cancer studies aiming at evaluating the role of IL-33 as a cytokine should systematically assess the function of ST2 in a particular experimental model.

\section{Role of IL-33 As a Transcriptional Regulator}

In addition to its extracellular role as an alarmin triggering ST2, signaling, IL-33 also has a nuclear function. Indeed, IL-33 has been early reported to be expressed in the nucleus of epithelial barrier tissues and lymphoid organs $(20,124)$. Nuclear IL-33 binds to the p65 subunit of NF- $\kappa \mathrm{B}$, thereby reducing NF- $\kappa \mathrm{B}$-dependent gene expression (22). A study using fibroblast-like synoviocytes from patients with rheumatoid arthritis indicated that downregulation of IL-33 results in increased NF- $\kappa$ B activity and in the production of pro-inflammatory molecules. These results suggest that nuclear IL-33 transcriptionally represses $\mathrm{NF}-\kappa \mathrm{B}$ and down-modulates inflammatory responses (125). Importantly, NF- $\kappa B$ signaling is not only central for innate immunity and inflammatory processes; it also plays an important role for cancer initiation and progression $(4,126)$. Therefore, it may be particularly relevant to address the contribution of intracellular IL-33 to NF- $\kappa B$ signaling in tumorigenesis, which has so far not been investigated. As nuclear IL-33 generally becomes upregulated in response to inflammation $(40,127)$, this may provide a possible control mechanism via a negative feedback loop. However, the physiological relevance of this mechanism should be assessed experimentally, as nuclear IL-33 has only limited potential for binding active NF- $\kappa B$ and thus preventing it from binding to DNA (22).
Therefore, this nuclear function of IL-33 may explain why certain investigations using St2-deficient mice may not fully recapitulate the findings from $I l 33^{-/-}$animals. While the role of nuclear IL-33 needs to be further addressed, e.g., for possible interaction with cancer-relevant transcription factors additional to NF- $\kappa B$, modulation of nuclear IL-33 expression likely represents a technical challenge for therapy.

Taken together, IL-33/ST2 signaling appears to mainly have a pro-tumorigenic role in cancer. However, several controversial reports provide caveats to a precipitated development of therapeutic strategies to block this pathway, and additional studies are required to unambiguously assess the contribution of IL-33 and ST2 to different cancer types.

\section{AUTHOR CONTRIBUTIONS}

PK: conception and writing of the manuscript; MHW: writing of the manuscript.

\section{ACKNOWLEDGMENTS}

The authors thank Lukas F. Mager for review and critical comments.

\section{FUNDING}

This work was supported by grants from the Swiss National Science Foundation (310030_138188 and 314730_163086), the Bern University Research Foundation, the Swiss Cancer League (Krebsliga Schweiz; KLS-3408-02-2014), and the San Salvatore Foundation (to PK). 


\section{REFERENCES}

1. Hanahan D, Weinberg RA. The hallmarks of cancer. Cell (2000) 100(1):57-70. doi:10.1016/S0092-8674(00)81683-9

2. Hanahan D, Weinberg RA. Hallmarks of cancer: the next generation. Cell (2011) 144(5):646-74. doi:10.1016/j.cell.2011.02.013

3. Hanahan D, Coussens LM. Accessories to the crime: functions of cells recruited to the tumor microenvironment. Cancer Cell (2012) 21(3):309-22. doi:10.1016/j.ccr.2012.02.022

4. Grivennikov SI, Greten FR, Karin M. Immunity, inflammation, and cancer. Cell (2010) 140(6):883-99. doi:10.1016/j.cell.2010.01.025

5. Koontongkaew S. The tumor microenvironment contribution to development, growth, invasion and metastasis of head and neck squamous cell carcinomas. J Cancer (2013) 4(1):66-83. doi:10.7150/jca.5112

6. Anand P, Kunnumakkara AB, Sundaram C, Harikumar KB, Tharakan ST, Lai OS, et al. Cancer is a preventable disease that requires major lifestyle changes. Pharm Res (2008) 25(9):2097-116. doi:10.1007/s11095-008-9661-9

7. Galon J, Costes A, Sanchez-Cabo F, Kirilovsky A, Mlecnik B, LagorcePages $\mathrm{C}$, et al. Type, density, and location of immune cells within human colorectal tumors predict clinical outcome. Science (2006) 313(5795):1960-4. doi:10.1126/science.1129139

8. Zhu Y, Ju S, Chen E, Dai S, Li C, Morel P, et al. T-bet and eomesodermin are required for T cell-mediated antitumor immune responses. J Immunol (2010) 185(6):3174-83. doi:10.4049/jimmunol.1000749

9. Chen LJ, Zheng X, Shen YP, Zhu YB, Li Q, Chen J, et al. Higher numbers of T-bet(+) intratumoral lymphoid cells correlate with better survival in gastric cancer. Cancer Immunol Immunother (2013) 62(3):553-61. doi:10.1007/ s00262-012-1358-6

10. Kim S, Karin M. Role of TLR2-dependent inflammation in metastatic progression. Ann N Y Acad Sci (2011) 1217:191-206. doi:10.1111/j.17496632.2010.05882.x

11. Kuper H, Adami HO, Trichopoulos D. Infections as a major preventable cause of human cancer. J Intern Med (2000) 248:171-83. doi:10.1046/j.1365-2796.2000.00742.x

12. Ekbom A, Helmick C, Zack M, Adami HO. Ulcerative colitis and colorectal cancer. A population-based study. N Engl J Med (1990) 323(18):1228-33. doi:10.1056/NEJM199011013231802

13. Jess T, Gamborg M, Matzen P, Munkholm P, Sorensen TI. Increased risk of intestinal cancer in Crohn's disease: a meta-analysis of population-based cohort studies. Am J Gastroenterol (2005) 100(12):2724-9. doi:10.1111/j.1572-0241.2005.00287.x

14. Mantovani A, Allavena P, Sica A, Balkwill F. Cancer-related inflammation. Nature (2008) 454(7203):436-44. doi:10.1038/nature07205

15. Candido J, Hagemann T. Cancer-related inflammation. JClin Immunol (2013) 33(Suppl 1):S79-84. doi:10.1007/s10875-012-9847-0

16. Schmitz J, Owyang A, Oldham E, Song Y, Murphy E, McClanahan TK, et al. IL-33, an interleukin-1-like cytokine that signals via the IL-1 receptor-related protein ST2 and induces T helper type 2-associated cytokines. Immunity (2005) 23(5):479-90. doi:10.1016/j.immuni.2005.09.015

17. Lamkanfi M, Dixit VM. IL-33 raises alarm. Immunity (2009) 31(1):5-7. doi:10.1016/j.immuni.2009.06.011

18. Lefrancais E, Roga S, Gautier V, Gonzalez-de-Peredo A, Monsarrat B, Girard JP, et al. IL-33 is processed into mature bioactive forms by neutrophil elastase and cathepsin G. Proc Natl Acad Sci U S A (2012) 109(5):1673-8. doi:10.1073/ pnas.1115884109

19. Liew FY, Pitman NI, McInnes IB. Disease-associated functions of IL-33: the new kid in the IL-1 family. Nat Rev Immunol (2010) 10(2):103-10. doi:10.1038/nri2692

20. Pichery M, Mirey E, Mercier P, Lefrancais E, Dujardin A, Ortega N, et al. Endogenous IL-33 is highly expressed in mouse epithelial barrier tissues, lymphoid organs, brain, embryos, and inflamed tissues: in situ analysis using a novel Il-33-LacZ gene trap reporter strain. J Immunol (2012) 188(7):3488-95. doi:10.4049/jimmunol.1101977

21. Cayrol C, Girard JP. IL-33: an alarmin cytokine with crucial roles in innate immunity, inflammation and allergy. Curr Opin Immunol (2014) 31:31-7. doi:10.1016/j.coi.2014.09.004

22. Ali S, Mohs A, Thomas M, Klare J, Ross R, Schmitz ML, et al. The dual function cytokine IL-33 interacts with the transcription factor NF-kappaB to dampen NF-kappaB-stimulated gene transcription. J Immunol (2011) 187(4):1609-16. doi:10.4049/jimmunol.1003080

23. Bergers G, Reikerstorfer A, Braselmann S, Graninger P, Busslinger M. Alternative promoter usage of the Fos-responsive gene Fit-1 generates mRNA isoforms coding for either secreted or membrane-bound proteins related to the IL-1 receptor. EMBO J (1994) 13(5):1176-88.

24. Iwahana H, Yanagisawa K, Ito-Kosaka A, Kuroiwa K, Tago K, Komatsu N, et al. Different promoter usage and multiple transcription initiation sites of the interleukin-1 receptor-related human ST2 gene in UT-7 and TM12 cells. Eur J Biochem (1999) 264(2):397-406. doi:10.1046/j.1432-1327.1999.00615.x

25. Hayakawa H, Hayakawa M, Kume A, Tominaga S. Soluble ST2 blocks interleukin-33 signaling in allergic airway inflammation. J Biol Chem (2007) 282(36):26369-80. doi:10.1074/jbc.M704916200

26. Miller AM. Role of IL-33 in inflammation and disease. J Inflamm (2011) 8(1):22. doi:10.1186/1476-9255-8-22

27. Brunner SM, Schiechl G, Falk W, Schlitt HJ, Geissler EK, Fichtner-Feigl S. Interleukin-33 prolongs allograft survival during chronic cardiac rejection. Transpl Int (2011) 24(10):1027-39. doi:10.1111/j.1432-2277.2011.01306.x

28. Duan L, Chen J, Zhang H, Yang H, Zhu P, Xiong A, et al. Interleukin-33 ameliorates experimental colitis through promoting Th2/Foxp3(+) regulatory T-cell responses in mice. Mol Med (2012) 18:753-61. doi:10.2119/ molmed.2011.00428

29. Liang Y, Jie Z, Hou L, Aguilar-Valenzuela R, Vu D, Soong L, et al. IL-33 induces nuocytes and modulates liver injury in viral hepatitis. J Immunol (2013) 190(11):5666-75. doi:10.4049/jimmunol.1300117

30. Schiering C, Krausgruber T, Chomka A, Frohlich A, Adelmann K, Wohlfert EA, et al. The alarmin IL-33 promotes regulatory T-cell function in the intestine. Nature (2014) 513(7519):564-8. doi:10.1038/ nature 13577

31. Layland LE, Mages J, Loddenkemper C, Hoerauf A, Wagner H, Lang $\mathrm{R}$, et al. Pronounced phenotype in activated regulatory $\mathrm{T}$ cells during a chronic helminth infection. J Immunol (2010) 184(2):713-24. doi:10.4049/ jimmunol.0901435

32. Burzyn D, Kuswanto W, Kolodin D, Shadrach JL, Cerletti M, Jang Y, et al. A special population of regulatory $\mathrm{T}$ cells potentiates muscle repair. Cell (2013) 155(6):1282-95. doi:10.1016/j.cell.2013.10.054

33. McHedlidze T, Waldner M, Zopf S, Walker J, Rankin AL, Schuchmann $\mathrm{M}$, et al. Interleukin-33-dependent innate lymphoid cells mediate hepatic fibrosis. Immunity (2013) 39(2):357-71. doi:10.1016/j.immuni. 2013.07.018

34. Molofsky AB, Van Gool F, Liang HE, Van Dyken SJ, Nussbaum JC, Lee J, et al. Interleukin-33 and interferon-gamma counter-regulate group 2 innate lymphoid cell activation during immune perturbation. Immunity (2015) 43(1):161-74. doi:10.1016/j.immuni.2015.05.019

35. Lu B, Yang $\mathrm{M}$, Wang Q. Interleukin-33 in tumorigenesis, tumor immune evasion, and cancer immunotherapy. J Mol Med (Berl) (2016) 94(5):535-43. doi:10.1007/s00109-016-1397-0

36. Leemans CR, Braakhuis BJ, Brakenhoff RH. The molecular biology of head and neck cancer. Nat Rev Cancer (2011) 11(1):9-22. doi:10.1038/ $\operatorname{nrc} 2982$

37. Chen SF, Nieh S, Jao SW, Wu MZ, Liu CL, Chang YC, et al. The paracrine effect of cancer-associated fibroblast-induced interleukin-33 regulates the invasiveness of head and neck squamous cell carcinoma. J Pathol (2013) 231(2):180-9. doi:10.1002/path.4226

38. Ishikawa K, Yagi-Nakanishi S, Nakanishi Y, Kondo S, Tsuji A, Endo K, et al. Expression of interleukin-33 is correlated with poor prognosis of patients with squamous cell carcinoma of the tongue. Auris Nasus Larynx (2014) 41(6):552-7. doi:10.1016/j.anl.2014.08.007

39. Chen Z, Fillmore CM, Hammerman PS, Kim CF, Wong KK. Nonsmall-cell lung cancers: a heterogeneous set of diseases. Nat Rev Cancer (2014) 14(8):535-46. doi:10.1038/nrc3775

40. Byers DE, Alexander-Brett J, Patel AC, Agapov E, Dang-Vu G, Jin X, et al. Long-term IL-33-producing epithelial progenitor cells in chronic obstructive lung disease. J Clin Invest (2013) 123(9):3967-82. doi:10.1172/ JCI65570

41. Makrinioti H, Toussaint M, Jackson DJ, Walton RP, Johnston SL. Role of interleukin 33 in respiratory allergy and asthma. Lancet Respir Med (2014) 2(3):226-37. doi:10.1016/S2213-2600(13)70261-3 
42. Liew FY, Girard JP, Turnquist HR. Interleukin-33 in health and disease. Nat Rev Immunol (2016) 16(11):676-89. doi:10.1038/nri.2016.95

43. Wang C, Chen Z, Bu X, Han Y, Shan S, Ren T, et al. IL-33 signaling fuels outgrowth and metastasis of human lung cancer. Biochem Biophys Res Commun (2016) 479(3):461-8. doi:10.1016/j.bbrc.2016.09.081

44. Akimoto M, Hayashi JI, Nakae S, Saito H, Takenaga K. Interleukin-33 enhances programmed oncosis of ST2L-positive low-metastatic cells in the tumour microenvironment of lung cancer. Cell Death Dis (2016) 7:e2057. doi:10.1038/cddis.2015.418

45. Tan WL, Jain A, Takano A, Newell EW, Iyer NG, Lim WT, et al. Novel therapeutic targets on the horizon for lung cancer. Lancet Oncol (2016) 17(8):e347-62. doi:10.1016/S1470-2045(16)30123-1

46. Ha CT, Li XH, Fu D, Moroni M, Fisher C, Arnott R, et al. Circulating interleukin-18 as a biomarker of total-body radiation exposure in mice, minipigs, and nonhuman primates (NHP). PLoS One (2014) 9(10):e109249. doi:10.1371/ journal.pone. 0109249

47. Ferlay J, Parkin DM, Steliarova-Foucher E. Estimates of cancer incidence and mortality in Europe in 2008. Eur J Cancer (2010) 46(4):765-81. doi:10.1016/ j.ejca.2009.12.014

48. Lu X, Kang Y. Organotropism of breast cancer metastasis. J Mammary Gland Biol Neoplasia (2007) 12(2-3):153-62. doi:10.1007/s10911-0079047-3

49. Jiang X, Shapiro DJ. The immune system and inflammation in breast cancer. Mol Cell Endocrinol (2014) 382(1):673-82. doi:10.1016/j.mce. 2013.06.003

50. Liu J, Shen JX, Hu JL, Huang WH, Zhang GJ. Significance of interleukin-33 and its related cytokines in patients with breast cancers. Front Immunol (2014) 5:141. doi:10.3389/fimmu.2014.00141

51. Kim JY, Lim SC, Kim G, Yun HJ, Ahn SG, Choi HS. Interleukin-33/ST2 axis promotes epithelial cell transformation and breast tumorigenesis via upregulation of COT activity. Oncogene (2015) 34(38):4928-38. doi:10.1038/ onc.2014.418

52. Yang ZP, Ling DY, Xie YH, Wu WX, Li JR, Jiang J, et al. The association of serum IL-33 and sST2 with breast cancer. Dis Markers (2015) 2015:516895. doi:10.1155/2015/516895

53. Jovanovic I, Radosavljevic G, Mitrovic M, Juranic VL, McKenzie AN, Arsenijevic N, et al. ST2 deletion enhances innate and acquired immunity to murine mammary carcinoma. Eur J Immunol (2011) 41(7):1902-12. doi:10.1002/eji.201141417

54. Jovanovic IP, Pejnovic NN, Radosavljevic GD, Pantic JM, Milovanovic MZ, Arsenijevic NN, et al. Interleukin-33/ST2 axis promotes breast cancer growth and metastases by facilitating intratumoral accumulation of immunosuppressive and innate lymphoid cells. Int J Cancer (2014) 134(7):1669-82. doi:10.1002/ijc.28481

55. Huang B, Pan PY, Li Q, Sato AI, Levy DE, Bromberg J, et al. Gr-1+CD115+ immature myeloid suppressor cells mediate the development of tumorinduced T regulatory cells and T-cell anergy in tumor-bearing host. Cancer Res (2006) 66(2):1123-31. doi:10.1158/0008-5472.CAN-05-1299

56. Raza A, Sood GK. Hepatocellular carcinoma review: current treatment, and evidence-based medicine. World J Gastroenterol (2014) 20(15):4115-27. doi:10.3748/wjg.v20.i15.4115

57. Waller LP, Deshpande V, Pyrsopoulos N. Hepatocellular carcinoma: a comprehensive review. World J Hepatol (2015) 7(26):2648-63. doi:10.4254/ wjh.v7.i26.2648

58. Zhang P, Liu XK, Chu Z, Ye JC, Li KL, Zhuang WL, et al. Detection of interleukin-33 in serum and carcinoma tissue from patients with hepatocellular carcinoma and its clinical implications. J Int Med Res (2012) 40(5):1654-61. doi:10.1177/030006051204000504

59. Bergis D, Kassis V, Ranglack A, Koeberle V, Piiper A, Kronenberger B, et al. High serum levels of the interleukin-33 receptor soluble ST2 as a negative prognostic factor in hepatocellular carcinoma. Transl Oncol (2013) 6(3):311-8. doi:10.1593/tlo.12418

60. Yang Y, Wang JB, Li YM, Zhao YU, Wang R, Wu Q, et al. Role of IL-33 expression in oncogenesis and development of human hepatocellular carcinoma. Oncol Lett (2016) 12(1):429-36. doi:10.3892/ol.2016.4622

61. Brunner SM, Rubner C, Kesselring R, Martin M, Griesshammer E, Ruemmele $\mathrm{P}$, et al. Tumor-infiltrating, interleukin-33-producing effector-memory $\mathrm{CD} 8(+) \mathrm{T}$ cells in resected hepatocellular carcinoma prolong patient survival. Hepatology (2015) 61(6):1957-67. doi:10.1002/ hep. 27728

62. Tyson GL, El-Serag HB. Risk factors for cholangiocarcinoma. Hepatology (2011) 54(1):173-84. doi:10.1002/hep.24351

63. Yamada D, Rizvi S, Razumilava N, Bronk SF, Davila JI, Champion MD, et al. IL-33 facilitates oncogene-induced cholangiocarcinoma in mice by an interleukin-6-sensitive mechanism. Hepatology (2015) 61(5):1627-42. doi:10.1002/hep. 27687

64. Kobayashi S, Werneburg NW, Bronk SF, Kaufmann SH, Gores GJ. Interleukin-6 contributes to Mcl-1 up-regulation and TRAIL resistance via an Akt-signaling pathway in cholangiocarcinoma cells. Gastroenterology (2005) 128(7):2054-65. doi:10.1053/j.gastro.2005.03.010

65. Wehbe H, Henson R, Meng F, Mize-Berge J, Patel T. Interleukin- 6 contributes to growth in cholangiocarcinoma cells by aberrant promoter methylation and gene expression. Cancer Res (2006) 66(21):10517-24. doi:10.1158/00085472.CAN-06-2130

66. Li J, Razumilava N, Gores GJ, Walters S, Mizuochi T, Mourya R, et al. Biliary repair and carcinogenesis are mediated by IL-33-dependent cholangiocyte proliferation. J Clin Invest (2014) 124(7):3241-51. doi:10.1172/ JCI73742

67. Carcas LP. Gastric cancer review. J Carcinog (2014) 13:14. doi:10.4103/ $1477-3163.146506$

68. Nagini S. Carcinoma of the stomach: a review of epidemiology, pathogenesis, molecular genetics and chemoprevention. World J Gastrointest Oncol (2012) 4(7):156-69. doi:10.4251/wjgo.v4.i7.156

69. Peek RM Jr, Crabtree JE. Helicobacter infection and gastric neoplasia. J Pathol (2006) 208(2):233-48. doi:10.1002/path.1868

70. Fox JG, Wang TC. Inflammation, atrophy, and gastric cancer. J Clin Invest (2007) 117(1):60-9. doi:10.1172/JCI30111

71. Yu XX, Hu Z, Shen X, Dong LY, Zhou WZ, Hu WH. IL-33 promotes gastric cancer cell invasion and migration via ST2-ERK1/2 pathway. Dig Dis Sci (2015) 60(5):1265-72. doi:10.1007/s10620-014-3463-1

72. Dhillon AS, Hagan S, Rath O, Kolch W. MAP kinase signalling pathways in cancer. Oncogene (2007) 26(22):3279-90. doi:10.1038/sj.onc.1210421

73. Wang Z, Si X, Xu A, Meng X, Gao S, Qi Y, et al. Activation of STAT3 in human gastric cancer cells via interleukin (IL)-6-type cytokine signaling correlates with clinical implications. PLoS One (2013) 8(10):e75788. doi:10.1371/ journal.pone. 0075788

74. Verma S, Kesh K, Ganguly N, Jana S, Swarnakar S. Matrix metalloproteinases and gastrointestinal cancers: impacts of dietary antioxidants. World J Biol Chem (2014) 5(3):355-76. doi:10.4331/wjbc.v5.i3.355

75. Brenner H, Kloor M, Pox CP. Colorectal cancer. Lancet (2014) 383(9927):1490-502. doi:10.1016/S0140-6736(13)61649-9

76. Vogelstein B, Fearon ER, Hamilton SR, Kern SE, Preisinger AC, Leppert M, et al. Genetic alterations during colorectal-tumor development. N Engl J Med (1988) 319(9):525-32. doi:10.1056/NEJM198809013190901

77. Terzic J, Grivennikov S, Karin E, Karin M. Inflammation and colon cancer. Gastroenterology (2010) 138(6):2101.e-14.e. doi:10.1053/j.gastro. 2010.01.058

78. Fearon ER. Molecular genetics of colorectal cancer. Annu Rev Pathol (2011) 6:479-507. doi:10.1146/annurev-pathol-011110-130235

79. Grivennikov SI, Cominelli F. Colitis-associated and sporadic colon cancers: different diseases, different mutations? Gastroenterology (2016) 150(4): 808-10. doi:10.1053/j.gastro.2016.02.062

80. Robles AI, Traverso G, Zhang M, Roberts NJ, Khan MA, Joseph C, et al. Whole-exome sequencing analyses of inflammatory bowel diseaseassociated colorectal cancers. Gastroenterology (2016) 150(4):931-43. doi:10.1053/j.gastro.2015.12.036

81. Mager LF, Wasmer MH, Rau TT, Krebs P. Cytokine-induced modulation of colorectal cancer. Front Oncol (2016) 6:96. doi:10.3389/fonc.2016.00096

82. Cui G, Qi H, Gundersen MD, Yang H, Christiansen I, Sorbye SW, et al. Dynamics of the IL-33/ST2 network in the progression of human colorectal adenoma to sporadic colorectal cancer. Cancer Immunol Immunother (2015) 64(2):181-90. doi:10.1007/s00262-014-1624-x

83. Mertz KD, Mager LF, Wasmer MH, Thiesler T, Koelzer VH, Ruzzante G, et al. The IL-33/ST2 pathway contributes to intestinal tumorigenesis in humans and mice. Oncoimmunology (2016) 5(1):e1062966. doi:10.1080/ 2162402X.2015.1062966 
84. Zhang Y, Davis C, Shah S, Hughes D, Ryan JC, Altomare D, et al. IL-33 promotes growth and liver metastasis of colorectal cancer in mice by remodeling the tumor microenvironment and inducing angiogenesis. Mol Carcinog (2017) 56:272-87. doi:10.1002/mc.22491

85. Liu X, Zhu L, Lu X, Bian H, Wu X, Yang W, et al. IL-33/ST2 pathway contributes to metastasis of human colorectal cancer. Biochem Biophys Res Commun (2014) 453(3):486-92. doi:10.1016/j.bbrc.2014.09.106

86. Maywald RL, Doerner SK, Pastorelli L, De Salvo C, Benton SM, Dawson EP, et al. IL-33 activates tumor stroma to promote intestinal polyposis. Proc Natl Acad Sci U S A (2015) 112(19):E2487-96. doi:10.1073/pnas.1422445112

87. Islam MS, Horiguchi K, Iino S, Kaji N, Mikawa S, Hori M, et al. Epidermal growth factor is a critical regulator of the cytokine IL-33 in intestinal epithelial cells. Br J Pharmacol (2016) 173:2532-42. doi:10.1111/bph.13535

88. Gounaris E, Erdman SE, Restaino C, Gurish MF, Friend DS, Gounari F, et al. Mast cells are an essential hematopoietic component for polyp development. Proc Natl Acad Sci U S A (2007) 104(50):19977-82. doi:10.1073/ pnas.0704620104

89. Blatner NR, Bonertz A, Beckhove P, Cheon EC, Krantz SB, Strouch M, et al. In colorectal cancer mast cells contribute to systemic regulatory T-cell dysfunction. Proc Natl Acad Sci U S A (2010) 107(14):6430-5. doi:10.1073/ pnas.0913683107

90. Cheon EC, Khazaie K, Khan MW, Strouch MJ, Krantz SB, Phillips J, et al. Mast cell 5-lipoxygenase activity promotes intestinal polyposis in APCDelta468 mice. Cancer Res (2011) 71(5):1627-36. doi:10.1158/00085472.CAN-10-1923

91. Waas ET, Wobbes T, Lomme RM, DeGroot J, Ruers T, Hendriks T. Matrix metalloproteinase 2 and 9 activity in patients with colorectal cancer liver metastasis. Br J Surg (2003) 90(12):1556-64. doi:10.1002/ bjs. 4346

92. Grivennikov S, Karin E, Terzic J, Mucida D, Yu GY, Vallabhapurapu S, et al. IL-6 and Stat3 are required for survival of intestinal epithelial cells and development of colitis-associated cancer. Cancer Cell (2009) 15(2):103-13. doi:10.1016/j.ccr.2009.01.001

93. Hu T, Yao Y, Yu S, Guo H, Han L, Wang W, et al. Clinicopathologic significance of CXCR4 and Nrf2 in colorectal cancer. J Biomed Res (2013) 27(4):283-90. doi:10.7555/JBR.27.20130069

94. Murakami T, Kawada K, Iwamoto M, Akagami M, Hida K, Nakanishi Y, et al. The role of CXCR3 and CXCR4 in colorectal cancer metastasis. Int J Cancer (2013) 132(2):276-87. doi:10.1002/ijc.27670

95. Wang TB, Hu BG, Liu DW, Shi HP, Dong WG. The influence of lentivirusmediated CXCR4 RNA interference on hepatic metastasis of colorectal cancer. Int J Oncol (2014) 44(6):1861-9. doi:10.3892/ijo.2014.2348

96. O’Donnell C, Mahmoud A, Keane J, Murphy C, White D, Carey S, et al. An antitumorigenic role for the IL-33 receptor, ST2L, in colon cancer. Br J Cancer (2016) 114(1):37-43. doi:10.1038/bjc.2015.433

97. Malik A, Sharma D, Zhu Q, Karki R, Guy CS, Vogel P, et al. IL-33 regulates the IgA-microbiota axis to restrain IL-1alpha-dependent colitis and tumorigenesis. J Clin Invest (2016) 126:4469-81. doi:10.1172/JCI88625

98. Wadleigh M, Tefferi A. Classification and diagnosis of myeloproliferative neoplasms according to the 2008 World Health Organization criteria. Int J Hematol (2010) 91(2):174-9. doi:10.1007/s12185-010-0529-5

99. Prick J, de Haan G, Green AR, Kent DG. Clonal heterogeneity as a driver of disease variability in the evolution of myeloproliferative neoplasms. Exp Hematol (2014) 42(10):841-51. doi:10.1016/j.exphem. 2014.07.268

100. Skoda RC, Duek A, Grisouard J. Pathogenesis of myeloproliferative neoplasms. Exp Hematol (2015) 43(8):599-608. doi:10.1016/j.exphem. 2015.06.007

101. Levescot A, Flamant S, Basbous S, Jacomet F, Feraud O, Anne Bourgeois E, et al. BCR-ABL-induced deregulation of the IL-33/ST2 pathway in CD34+ progenitors from chronic myeloid leukemia patients. Cancer Res (2014) 74(10):2669-76. doi:10.1158/0008-5472.CAN-13-2797

102. Mager LF, Riether C, Schurch CM, Banz Y, Wasmer MH, Stuber R, et al. IL-33 signaling contributes to the pathogenesis of myeloproliferative neoplasms. JClin Invest (2015) 125(7):2579-91. doi:10.1172/ JCI77347

103. Gao X, Wang X, Yang Q, Zhao X, Wen W, Li G, et al. Tumoral expression of IL-33 inhibits tumor growth and modifies the tumor microenvironment through CD8+ T and NK cells. J Immunol (2015) 194(1):438-45. doi:10.4049/ jimmunol.1401344

104. Villarreal DO, Wise MC, Walters JN, Reuschel EL, Choi MJ, Obeng-Adjei N, et al. Alarmin IL-33 acts as an immunoadjuvant to enhance antigen-specific tumor immunity. Cancer Res (2014) 74(6):1789-800. doi:10.1158/0008-5472. CAN-13-2729

105. Rose WA II, Okragly AJ, Patel CN, Benschop RJ. IL-33 released by alum is responsible for early cytokine production and has adjuvant properties. Sci Rep (2015) 5:13146. doi:10.1038/srep13146

106. Lim HX, Choi S, Cho D, Kim TS. IL-33 inhibits the differentiation and immunosuppressive activity of granulocytic myeloid-derived suppressor cells in tumor-bearing mice. Immunol Cell Biol (2017) 95(1):99-107. doi:10.1038/ icb. 2016.72

107. Bessa J, Meyer CA, de Vera Mudry MC, Schlicht S, Smith SH, Iglesias A, et al. Altered subcellular localization of IL-33 leads to non-resolving lethal inflammation. J Autoimmun (2014) 55:33-41. doi:10.1016/j.jaut.2014.02.012

108. Talabot-Ayer D, Martin P, Vesin C, Seemayer CA, Vigne S, Gabay C, et al. Severe neutrophil-dominated inflammation and enhanced myelopoiesis in IL-33-overexpressing CMV/IL33 mice. J Immunol (2015) 194(2):750-60. doi:10.4049/jimmunol.1402057

109. Sun P, Ben Q, Tu S, Dong W, Qi X, Wu Y. Serum interleukin-33 levels in patients with gastric cancer. Dig Dis Sci (2011) 56(12):3596-601. doi:10.1007/ s10620-011-1760-5

110. Hu LA, Fu Y, Zhang DN, Zhang J. Serum IL-33 as a diagnostic and prognostic marker in non-small cell lung cancer. Asian Pac J Cancer Prev (2013) 14(4):2563-6. doi:10.7314/APJCP.2013.14.4.2563

111. Gramatzki D, Frei K, Cathomas G, Moch H, Weller M, Mertz KD. Interleukin-33 in human gliomas: expression and prognostic significance. Oncol Lett (2016) 12(1):445-52. doi:10.3892/ol.2016.4626

112. Rossle M, Cathomas G, Bonapace L, Sachs M, Dehler S, Storz M, et al. Interleukin-33 expression indicates a favorable prognosis in malignant salivary gland tumors. Int J Surg Pathol (2016) 24(5):394-400. doi:10.1177/1066896916633856

113. Saranchova I, Han J, Huang H, Fenninger F, Choi KB, Munro L, et al. Discovery of a metastatic immune escape mechanism initiated by the loss of expression of the tumour biomarker interleukin-33. Sci Rep (2016) 6:30555. doi:10.1038/srep30555

114. Gluck J, Rymarczyk B, Rogala B. Serum IL-33 but not ST2 level is elevated in intermittent allergic rhinitis and is a marker of the disease severity. Inflamm Res (2012) 61(6):547-50. doi:10.1007/s00011-012-0443-9

115. Tamagawa-Mineoka R, Okuzawa Y, Masuda K, Katoh N. Increased serum levels of interleukin 33 in patients with atopic dermatitis. J Am Acad Dermatol (2014) 70(5):882-8. doi:10.1016/j.jaad.2014.01.867

116. Xia J, Zhao J, Shang J, Li M, Zeng Z, Zhao J, et al. Increased IL-33 expression in chronic obstructive pulmonary disease. Am J Physiol Lung Cell Mol Physiol (2015) 308(7):L619-27. doi:10.1152/ajplung.00305.2014

117. Oboki K, Ohno T, Kajiwara N, Arae K, Morita H, Ishii A, et al. IL-33 is a crucial amplifier of innate rather than acquired immunity. Proc Natl Acad Sci US A (2010) 107(43):18581-6. doi:10.1073/pnas.1003059107

118. Corbin AS, Agarwal A, Loriaux M, Cortes J, Deininger MW, Druker BJ. Human chronic myeloid leukemia stem cells are insensitive to imatinib despite inhibition of BCR-ABL activity. J Clin Invest (2011) 121(1):396-409. doi:10.1172/jci35721ds1

119. Qin L, Dominguez D, Chen S, Fan J, Long A, Zhang M, et al. Exogenous IL-33 overcomes T cell tolerance in murine acute myeloid leukemia. Oncotarget (2016) 7(38):61069-80. doi:10.18632/oncotarget.11179

120. Xiao P, Wan X, Cui B, Liu Y, Qiu C, Rong J, et al. Interleukin 33 in tumor microenvironment is crucial for the accumulation and function of myeloid-derived suppressor cells. Oncoimmunology (2016) 5(1):e1063772. doi:10.1080/2162402X.2015.1063772

121. Kouzaki H, Iijima K, Kobayashi T, O'Grady SM, Kita H. The danger signal, extracellular ATP, is a sensor for an airborne allergen and triggers IL-33 release and innate Th2-type responses. J Immunol (2011) 186(7):4375-87. doi:10.4049/jimmunol.1003020

122. Gordon ED, Simpson LJ, Rios CL, Ringel L, Lachowicz-Scroggins ME, Peters $\mathrm{MC}$, et al. Alternative splicing of interleukin-33 and type 2 inflammation in asthma. Proc Natl Acad Sci U S A (2016) 113(31):8765-70. doi:10.1073/ pnas. 1601914113 
123. Gangemi S, Allegra A, Profita M, Saitta S, Gerace D, Bonanno A, et al. Decreased plasma levels of IL-33 could contribute to the altered function of Th2 lymphocytes in patients with polycythemia vera and essential thrombocythemia. Cancer Invest (2013) 31(3):212-3. doi:10.3109/07357907. 2013.764566

124. Carriere V, Roussel L, Ortega N, Lacorre DA, Americh L, Aguilar L, et al. IL-33, the IL-1-like cytokine ligand for ST2 receptor, is a chromatinassociated nuclear factor in vivo. Proc Natl Acad Sci US A (2007) 104(1):282-7. doi:10.1073/pnas.0606854104

125. Lee EJ, So MW, Hong S, Kim YG, Yoo B, Lee CK. Interleukin-33 acts as a transcriptional repressor and extracellular cytokine in fibroblast-like synoviocytes in patients with rheumatoid arthritis. Cytokine (2016) 77:35-43. doi:10.1016/j.cyto.2015.10.005

126. Hoesel B, Schmid JA. The complexity of NF-kappaB signaling in inflammation and cancer. Mol Cancer (2013) 12:86. doi:10.1186/1476-4598-12-86
127. Prefontaine D, Nadigel J, Chouiali F, Audusseau S, Semlali A, Chakir J, et al. Increased IL-33 expression by epithelial cells in bronchial asthma. J Allergy Clin Immunol (2010) 125(3):752-4. doi:10.1016/j.jaci.2009.12.935

Conflict of Interest Statement: The authors declare that the research was conducted in the absence of any commercial or financial relationships that could be construed as a potential conflict of interest.

Copyright $\odot 2017$ Wasmer and Krebs. This is an open-access article distributed under the terms of the Creative Commons Attribution License (CC BY). The use, distribution or reproduction in other forums is permitted, provided the original author(s) or licensor are credited and that the original publication in this journal is cited, in accordance with accepted academic practice. No use, distribution or reproduction is permitted which does not comply with these terms. 